\title{
From Communicative Competence to Interactional Competence: A New Outlook to the Teaching of Spoken English
}

\author{
Dongyun Sun \\ College English Center, Fudan University, Shanghai, China
}

\begin{abstract}
This paper reexamines communicative competence by studying several representative models. After examining some inherent defects with today's communicative spoken English teaching, the author highlights the importance of strategic competence and proposes a shift to interactional competence because conversational strategies can be best acquired and studied in the light of complete conversational loops. The author also proposes a model for the teaching of spoken English and demonstrates how conversational strategies function throughout the whole conversational loop. It is also hoped that spoken English testing should take the form of bi-directional or multi-directional conversation among candidates so that the teaching of conversational strategies can better promote the development of interactional competence.
\end{abstract}

Index Terms - communicative competence, conversational strategy, interactional competence, spoken English teaching and testing, conversational loop

Perhaps the majority of language teachers today, when asked to identify the methodology they employ in their classroom, mention "communicative" as the methodology of choice. However, when they are pressed to give a detailed account of what they mean by it, their explanations vary widely.

\section{Communicative Competence In COLlEge English Teaching}

College English teaching has been one of the greatest concerns in higher education in China. College students spend a large portion of their spare time on English learning, but many of them still feel frustrated by their poor command of English in usage. Faced with the accusation of being responsible for such "dumb English", teachers and researchers have been actively exploring methods for improving students' competence for using English. According to the "College English Curriculum Requirements", "the object of College English is to develop students' ability to use English in an all-round way, especially in listening and speaking, so that in their future work and social interactions they will be able to exchange information effectively through both spoken and written channels, and at the same time they will be able to enhance their ability to study independently and improve their cultural quality so as to meet the needs of China's social development and international exchanges." (Higher Education Department of the Ministry of Education, 2007) This statement shows manifestly that communicative competence is placed at the top of the priority list.

Today most college English teachers have consciously adopted the communicative approach in their teaching, but students still complain about their poor communicative competence. It is therefore important for us to reexamine this key concept and find a better solution.

\section{Overview of Communicative Competence}

Communicative competence is one of the key notions in second language acquisition. Hymes $(1971,1972)$ introduced the notion of "communicative competence" as opposed to Chomsky's dichotomy of "competence" and "performance". He points out that it is more important for language users to understand the social rules for the actual use of a language for daily interaction. Hymes' communicative competence model consists of two areas of competence: grammatical competence and sociolinguistic competence, and "ability for use." Communicative competence is separated from the actual performance in real-time, concrete situations. Hymes' communicative competence model can be illustrated as follows: 


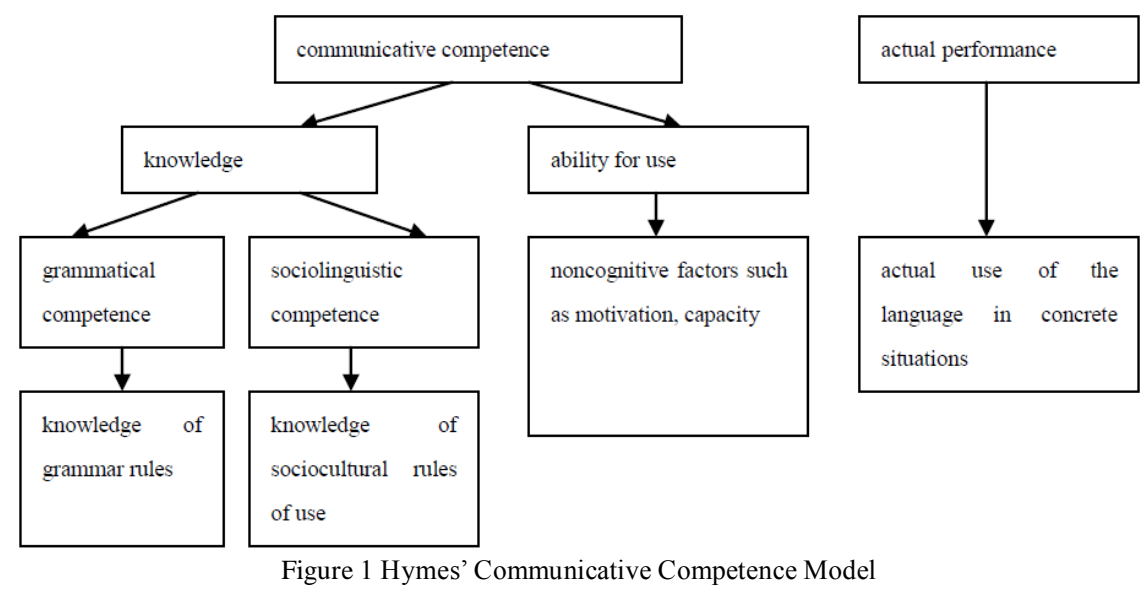

Hymes' attention to communicative competence inspired a number of models of such competence. The two world famous follow-up studies between 1980 and 1990 were conducted by Canale \& Swain (1980) and Bachman (1990). In the context of L2 teaching, Canale \& Swain (1980, p.20) defined communicative competence as "a synthesis of knowledge of basic grammatical principles, knowledge of how language is used in social contexts to perform communicative functions, and knowledge of how utterances and communicative functions can be combined according to the principle of discourse".

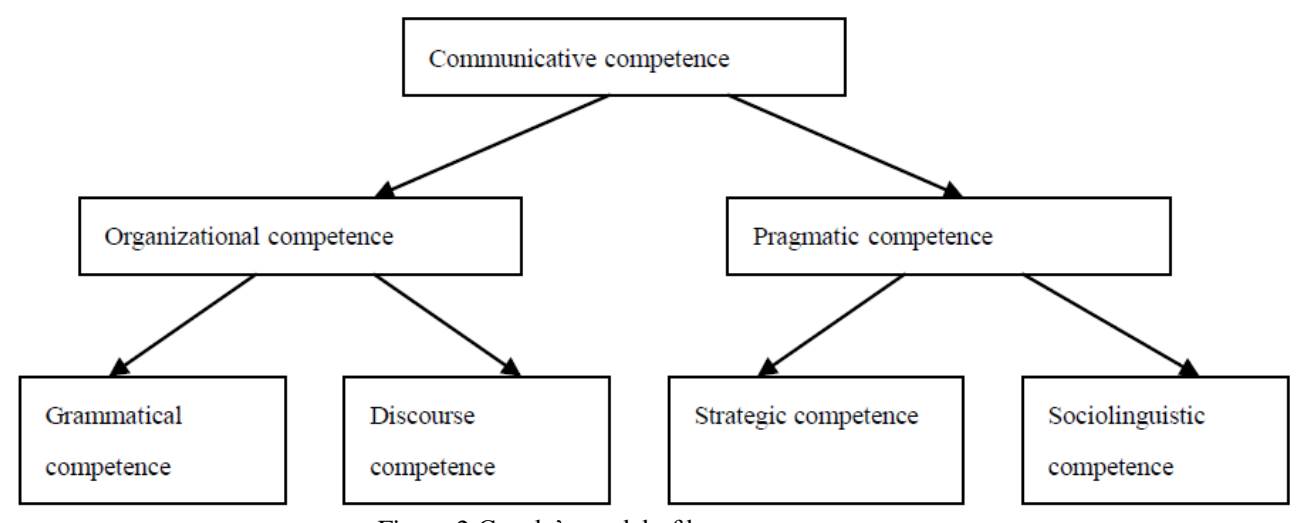

Figure 2 Canale's model of language competence

A similar theoretical framework for communicative competence was developed by Bachman (1988, 1990) and Bachman \& Palmer (1982, 1996). In their 1996 model of communicative ability, Bachman \& Palmer distinguished three components: "organizational knowledge," "pragmatic knowledge," and "strategic competence." Organizational knowledge includes both grammatical knowledge and textual knowledge (covering cohesion). Pragmatic knowledge includes both knowledge of sociolinguistic rules and functional knowledge ("illocutionary competence," as in Bachman, 1990). Strategic competence involves the ability to make the most effective use of available abilities to carry out a given task. Strategic competence is conceived of "as a set of metacognitive components, or strategies, which can be thought of as higher order executive processes that provide a cognitive management function for language use, as well as in other cognitive activities" (Bachman \& Palmer, 1996, p.70). Three basic areas of strategic competence are identified: goal setting, planning, and assessment (Verhoeven \& Vermeer, 2002).

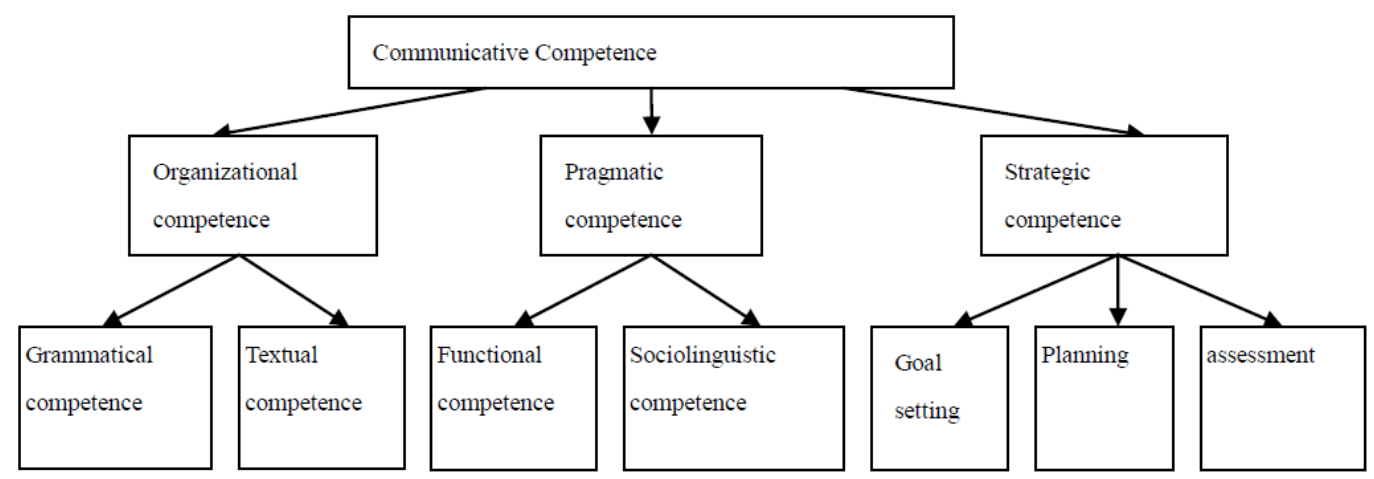

Figure 3 Bachman's Communicative Competence Model (after Bachman \& Palmer 1996, p.68) 
Wen (1999) argues for the importance of cross-cultural communication in the study of communicative competence. She believes that the ability for handling cultural differences in interactions should be integrated into the study of communicative competence. Based on the analysis of these models, Wen proposed her own model for "cross-cultural communicative competence", in which "cross-cultural competence" constitutes a component parallel to communicative competence.

While different researchers have been discussing the definition and classification of communicative competence and have proposed different models, the controversy usually revolves around two core competences: how correctly learners can use the foreign language and how appropriately learners can use the foreign language. The former, defined as "organizational competence" (Canale, 1980), refers to the learner's lexical, syntactic and stylistic competences. By contrast, the latter, defined variously as "pragmatic competence" (Canale, 1980, p.20) or "sociolinguistic competence" (Savignon, 1983, p.87) or "intercultural competence" (Wen, 1999, p.9; Sercu, 2005, p.3), concerned about how the learner uses the language appropriately in a specified context to enable successful communication. For the sake of convenience, the author suggests that they should be termed respectively as "linguistic competence" and "strategic competence". Linguistic competence has always earned the greatest attention in language learning, but strategic competence still lacks due attention. Thus striking a proper balance between these two elements has become a great challenge for foreign language teachers in China.

\section{Present Situation of Communicative Competence in Language Teaching in China}

Today, most foreign language educators have readily embraced the communicative objective as the overriding principle underlying activities in today's classrooms. The communicative approach has been widely adopted in teaching practice. Despite growing concern over the development of communicative competence, the present teaching of spoken English is still largely unsuccessful, incurring complaints from many learners. The problems can be summed up as follows:

\section{A. Overdue Bias on Linguistic Competence Rather Than Strategic Competence}

Both Wen (1999) and other researchers have long ago reached consensus that "strategic competence" should be added to the classification of communicative competence, but it is not yet incorporated in spoken English teaching. Language educators have been dedicated to developing learners' linguistic competence during the history of language teaching, and this is embodied in most approaches to language learning such as grammar-translation approach, audio-lingual approach, direct approach and communicative approach. By contrast, teachers' long-standing negligence of communicative strategies in classroom teaching has resulted in learners' lack of strategic competence-students always find themselves unable to interact successfully with people in English. Just as Wang (2004) points out, Chinese students tend to use a few strategies repeatedly in their conversation; they show poor management capacity for conversational strategies, and are deficient in turn-taking, turn control and interactional strategies. This has led to some negative influences on their fluency and speed of spoken English.

Most teachers lay special emphasis on grammatical correctness and hasten to point out speech errors of learners. With the introduction of communicative approach, an increasing number of educators have realized the importance of developing learners' speaking competence, but grammar teaching is still dominant in the foreign language classroom. Learners are taught a few typical responses to certain questions in some typical communicative contexts, but their pragmatic competence remains poor, or in other words, learners feel inadequate as to how to fulfill a communicative task appropriately in interactions.

Such inadequacies are by no means strange to Chinese teachers. In tests of different levels, students have shown a clear lack of communicative strategies, which hinders their communicative performance. This demonstrates a long-standing negligence from teachers and researchers-despite their attention to discrete functional skills, most of them are simply unaware of regular communicative strategies in handling routine interactions. A sample from College English Learner's Spoken Corpus (COLSEC) on CD-ROM can fully demonstrate the lack of communicative strategies in Chinese students:

<interlocutor> OK. Now would you please briefly introduce yourselves to each other. Remember you should not mention the name of your university. </interlocutor $>$

$<$ sp1 $>$ Thank you. I begin, all right? </sp1>

<interlocutor $>$ OK. </interlocutor>

$<$ sp1 $>$... You know my name and my admission ticket. I'm a junior student majoring electronic communication. I enjoy rich studying [Pu-r] and I really appreciate this chance to show my spoken English. Since I'm a little tense now, I have never taken this [Wth-d] kind of spoken English test, I'm afraid I'll make some... grammar mistakes that... are very obscure, I wish you all [P21-r] will tolerate them, and I will try my best to avoid [Wv-w] them. Is that... that's all, thank you, thank you for listening.

<interlocutor $>$ OK, OK. Now... now we have known each other, we can do some group work.

$\ldots$

--an excerpt from 010039.txt in COLSEC on CD-ROM (Yang \& Wei, 2005) 
This excerpt from a spoken test shows that the learner has made some pragmatic mistakes, but her grammatical competence is quite acceptable. In the first response to the interlocutor, she states some words that are clearly prepared beforehand, but the majority of her statement is simply unnecessary. She has committed the error of overdue modesty that is typical of traditional Chinese culture - by contrast, people in Western culture seem more straightforward, as they would usually come directly to the topic in a conversation.

<sp1> Ok. Ah my topic is about eh communicating with native speakers and reading as wide widely as possible. Er as $\mathrm{mn}$ as we have passed the CET test, maybe there will be less English er lessons in our school. So we en it is very important for us [P-1] to learn English by ourselves [P-1]. And first way is to communicate with native speakers because by speaking with native speakers, we can eh learn some er we can know how to use our English er bu- er how to communicate with others. And as native speakers, they speak native English. Er we can know how to use English in the right way. Er and also we can learn some culture backgrounds and different eh world [Ml] views of native speakers. And second is to read as widely as possible. Mn er after after er speaking with other people, you should er also have some work of reading because from reading you can not er not en not only the not only know er your er those words and expressions you learned from school, and also you can read some ori- er original materials, and you can further further your world [Ml] views and further [Wt-d] er not only in the field of English language, but also the other langu$\mathrm{mn}$ al-also in other er fields. So reading as widely as possible is also a very important way to improve our English. $</ \mathrm{sp} 1>$

...

--an excerpt from 030259.txt in COLSEC on CD-ROM (Yang \& Wei, 2005)

As shown in this speech, the speaker shows pretty good command of English grammar. However, whenever he has problems in expression, he uses very few communicative strategies repeatedly, which greatly damages his fluency. As we can see, there is a striking overuse of stalling strategy. He overuses "er", "en", "eh" to keep the speech going. He also uses self-repetition as a stalling strategy, but such a repetition as "not er not en not only the not only" is too monotonous. Actually, he might as well use a variety of fillers such as "well”, "sort of", "you know”, "as we can see”, etc.

\section{B. Overdue Bias on Discrete Skills Rather Than Interactional Skills}

Textbooks on spoken English are usually arranged according to functional-notional situations so that learners are taught a specific skill of making inquiries or responses within one given context. Yu \& Li (2002) can be seen as a typical representative - the whole textbook is composed of 16 units, each including one specific communicative function such as inquiring about future activities, expressing hope, ordering a meal at a restaurant, and seeing the doctor. These functions are taught in typical dialogues in the format of one response to one inquiry. Such simulated communicative situations can never cover all the functions in real situations, because teachers have not told students how to interact successfully with people within a given context and fulfill a complete loop of conversation. As a result, learners may be able to respond to one question or another in a given format, but can hardly adjust to new challenges within the context. Ultimately, despite their discrete skills, many of them still lack the interactional skills that are required in real communicative situations. In other words, they lack the necessary strategic competence to fulfill their communicative goals. Just as Guo (2002) points out, college students usually feel awkward in authentic conversations and discussions, which are manifested in both their inability to use conversational skills in starting, changing or ending a topic and their inability to perform natural communication with appropriate communicative strategies. He concludes that these show that students are only capable of one-way communication and have not yet mastered the genuine communicative competence-the interactional communicative competence.

In the speech exercises of college English class, students are taught some discrete functional-notional skills in a few communicative situations. A typical one goes like this:

TABLE 1

A TYPICAL COMMUNICATIVE SITUATION IN COLLEGE ENGLISH TEXTBOOKS (AN EXCERPT FROM STUDENTS BOOK, COLLEGE ENGLISH-LISTENING AND SPEAKING COURSE 2)

\begin{tabular}{|l|l|}
\hline Communicative Function: & Buying a Meal at a School Canteen or a Fast Food Restaurant \\
\hline Counter hand & Customer \\
\hline What'll you have? & I'd like a cheeseburger, an order of fries and a chocolate shake. \\
\hline Can I help you? & Yes, I'd like... \\
\hline What do you want? & I think I'll have... \\
\hline What are you going to have? & I'll try a chicken sandwich. \\
\hline What can I get you? & A bowl of wonton. \\
\hline To eat here or to go? & I'll eat here. \\
\hline ... & $\ldots$ \\
\hline
\end{tabular}

The communicative function above is typical of most college English textbooks. A glance at the inquiries and responses reveals that these sentence drills are simply an extension of classroom grammatical practices. Students are required to follow the given formats to produce the grammatically correct answers that are expected, no more no less. All answers conform perfectly to the four Gricean maxims of the Cooperative Principle: the maxim of quality, the 
maxim of quantity, the maxim of relation and the maxim of manner (Levinson, 1983). However, such fixed patterns yield no conversational implicature and thus are lacking in creativity and subtlety. According to a survey of 35 adult learners by Gao (2002), most of them have gained good linguistic competence, as is shown by the fact that $80 \%$ of them passed the CET-4 examination, yet they still commit many pragmatic errors in spoken English.

\section{INTERACTIONAL COMPETENCE IN SPOKEN ENGLISH TEACHING}

\section{A. Interactional Competence vs. Communicative Competence}

When communicative competence is developed in discrete functional-notional fields, prescribed patterns of conversation replaces the spontaneous and vivid interactions, and the whole teaching is reduced to a structural approach-learners just need to parrot some given sentence patterns to react to given contexts. Therefore some researchers such as He \& Young (1998), and Young (1999) propose an alternative theoretical framework to communicative competence - interactional competence theory-as a replacement for communicative competence, because they believe that "individuals do not acquire a general, practice-independent competence; rather they acquire a practice-specific interactional competence by participating with more experienced others in specific interactive practices". (He \& Young, 1998, p.7)

Kramsch (1986, p.367) in her article 'From Language Proficiency to Interactional Competence' defines the term 'interaction' as “...interaction entails negotiating intended meanings, i.e., adjusting one's speech to the effect one intends to have on the listener. It entails anticipating the listener's response and possible misunderstandings, clarifying one's own and the other intentions and arriving at the closed possible watch between intended, perceived, and anticipated meanings." Therefore interactional competence is "a theory of the knowledge that participants bring to and realize in interaction and includes an account of how this knowledge is acquired" (Young 1999, p.118). For example, interactional details are important in sociocultural theories because "the language that we learn to use in these practices comes to us packaged with particular histories, already dialogized, spoken about, and evaluated and we encounter it already "used" (Hall 1995, p.218).

Interaction and the local nature of language competence are combined with another fundamental principle of the theory of interactional competence: co-construction. Co-construction is defined as "the joint creation of a form, interpretation, stance, action, activity, identity, institution, skill, ideology, emotion, or other culturally meaningful reality" (Jacoby \& Ochs 1995, p.171) According to interactional competence, knowledge of language is jointly co-created by all participants in interaction (He \& Young 1998; Young 1999).

\section{B. Interactional Competence and Spoken English Teaching}

\section{Research of communicative strategies in spoken English teaching}

Interactional competence differs from communicative competence in its focus on interactions from a constructivist approach to the development of spoken English - they believe that conversational competence is co-constructed by speakers involved in the conversation. Thus it calls for greater attention to interactions between learners. This approach is especially enlightening to researchers and language teachers in China because it is more applicable to the situation for the development of spoken English for Chinese students. Researches in second language acquisition and communicative competence derive a great deal from training to new immigrants who face a native language environment, but not all these theories and discoveries are applicable to the Chinese practice (Wang 2001, p.68). It is manifest that students in China practice their spoken English with Chinese classmates in a cultural context of Chinese society, and thus it is much more difficult for them to develop intercultural competence with peers in a homogeneous culture. The shift to interactional competence affirms the critical significance of practicing spoken English with Chinese fellow students.

The focus on interactional competence also highlights communicative strategies and raises strategic competence to a prevailing position in spoken English teaching and learning. Strategic competence has been acknowledged as a part of communicative competence for over two decades, but the teaching of spoken English has hardly incorporated any strategic element in communicative strategies. Therefore students in China need more training to enable them to fulfill interactional tasks in authentic situations. Some researchers such as Wen (1999) have already realized the importance of communicative strategies in spoken English teaching. Language teachers and researchers (Wang 2002; Zeng \& Li, 2005; Kong, 2004) have experimented the incorporation of conversational strategies in spoken English teaching. Results show that students in the experiment group show better fluency in spoken English over those in the control group, and their confidence for spoken English improves significantly.

Despite such findings, there is hardly any textbook of spoken English in China that devotes a special section to communicative strategies or even mentions them at all. In fact, the classification of communicative strategies per se is subject to controversy, and some researchers even disapprove of the training of communicative strategies by the allegation that communicative strategies in the first language can transfer to second language acquisition (Kong, 2004, p.4). However, there is no denying that training in communicative strategies has yielded tangible progress in learners' spoken English. It is high time that teachers paid due attention to this issue.

\section{The integration of communicative strategies in interactional competence}

Despite the fact that a growing number of language teachers have realized the importance of incorporating communicative strategies in the development of learners' communicative competence, there seems to be a gap between 
theory and practice, which hinders the integration and application of communicative strategies in spoken English practice. On the one hand, some teachers offer sample conversational situations that feature broken or discrete functional skills rather than complete conversations of interaction; on the other hand, they impart communicative strategies to students, hoping that these strategies will enhance their performance in the interaction. It is evident that the discrete functional skills as a continuance of traditional grammatical drills are simply incompatible with interaction-based communicative strategies. Therefore when communicative strategies are evaluated with the orientation of interactional competence, these strategies are best taught or learned in interactions. To be specific, interactions in classroom teaching should be embodied in complete loops of conversation because a loop is a unit of conversation in which communicative strategies can be effectively evaluated. Moreover, the constructivist nature of interactional competence presupposes that communicative strategies can be co-constructed by peers during a loop of conversation-learners do not merely learn the strategies, but construct them during the real situations. Under the guidance of this principle, learners are expected to develop their communicative strategies in such a linear model:

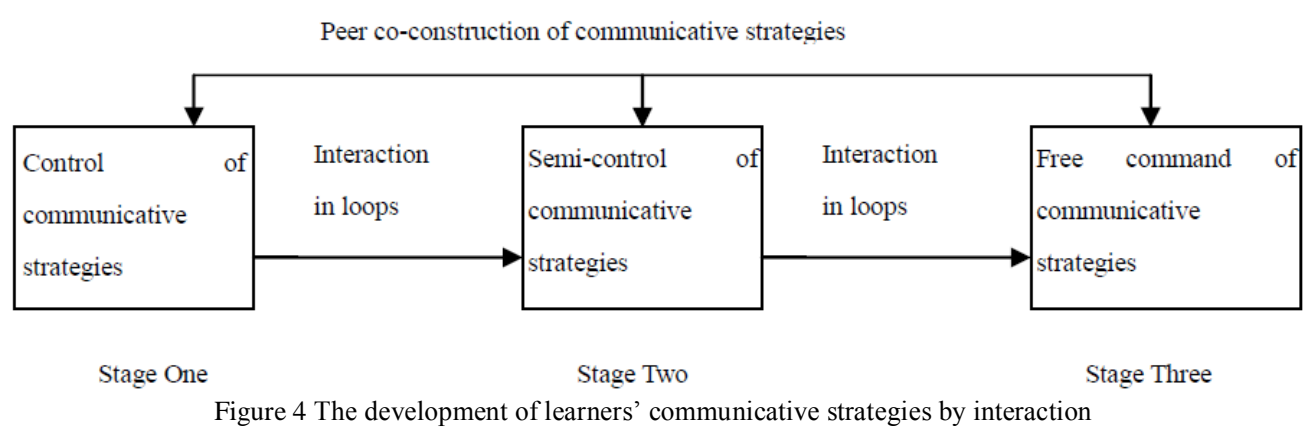

As shown in the figure, to achieve the goal of developing learners' interactional competence, learners should learn to co-construct their communicative strategies in interactions. As a result, their interactional competence grows alongside with their practice of communicative strategies in conversational loops. At the beginning (Stage One), they need good control and supervision of communicative strategies that are taught to them by teachers. Gradually, with their practice in interactions, their awareness of these strategies improves, and the control of communicative strategies by teachers recedes and finally learners can command these strategies with ease and proficiency. Therefore the author proposes that the traditional discrete functional-notional situation for communication should be expanded to a complete loop of conversation, with communicative strategies serving as links between different functions. Thus a model of strategy-reinforced interactions can be illustrated in the following sample:

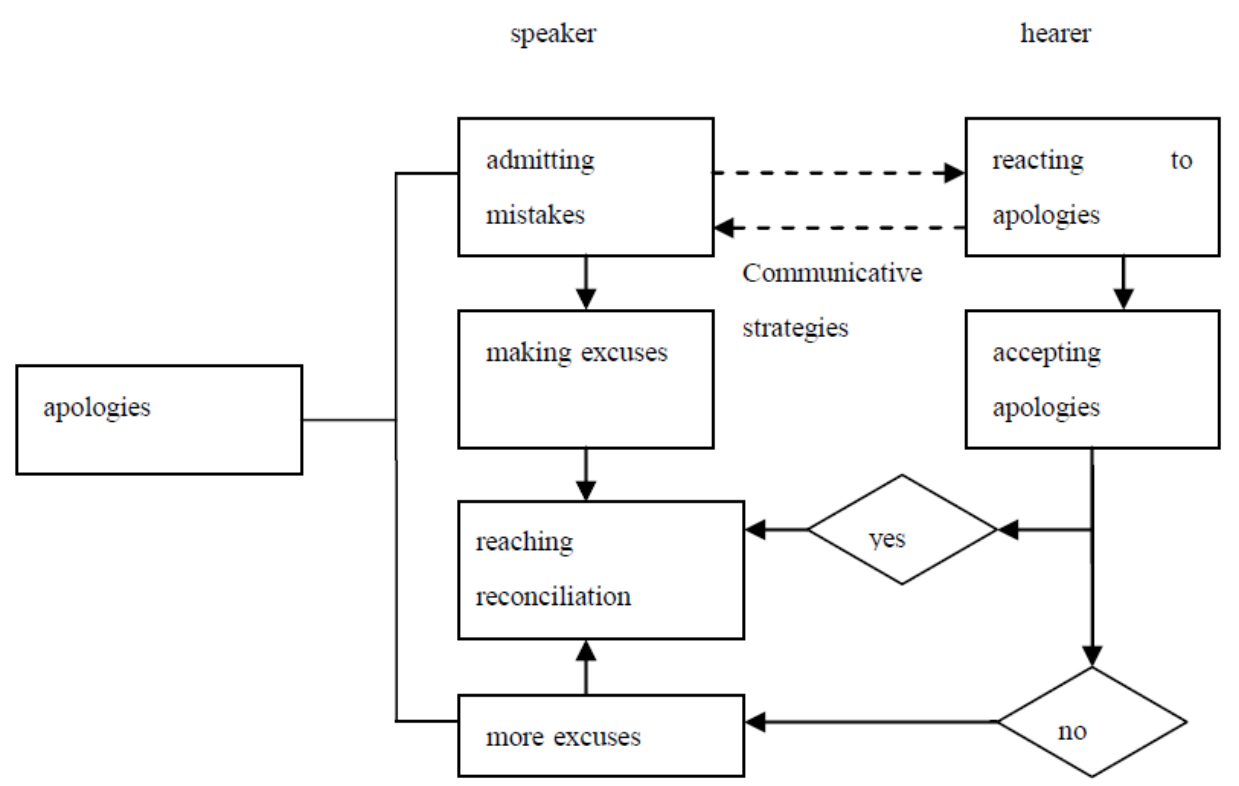

Figure 5 A conversational loop of strategy-reinforced interaction: apology and reconciliation

This demonstrates a complete conversational loop in which the speaker interacts with the listener on making apologies. Both of them learn to use communicative strategies to keep the conversation going smoothly and reduce unnecessary frictions and misunderstandings. A complete loop will also include different possibilities so that learners will learn to apply the strategies to handling different alternatives that may arise in real communicative situations. During different stages or possibilities of interactions, learners co-construct their knowledge of strategic competence 
and improve their fluency and confidence.

In interactional practice of communicative strategies, teachers should preferably combine "situations" with "functions" or "notions" to achieve a simulated virtual environment. Here the author suggests a constructivist approach to spoken English learning, as it will expectedly stimulate learners' motivation and enthusiasm towards co-construction of knowledge. For instance, a collaborative learning project targeting at reaching a business agreement through negotiation can be established in the light of project-based learning (PBL). With the purpose of building better interactional competence, this project will require learners to accomplish all the inevitable conversational loops during the negotiation process, during which they will actively translate communicative strategies into action. Thus it constitutes a strategy-reinforced interactional situation for the practice of spoken English.

\section{Interactional Competence and Spoken English Testing}

Spoken English tests in China constitute an integral part in many influential examinations such as Business English Certificate examination (BEC), TOEFL and College Entrance Examinations. They are also optional components in College English Tests (CET), Test for English Majors (TEM), and other examinations. With the ever-growing concern of learners over spoken English communicative competence, a large number of students take different spoken English tests. Therefore the design of spoken English tests will be closely associated with classroom teaching.

Given the focus on interactional competence in this paper, it is natural to assume that spoken English tests should preferably test the conversational strategies and skills of candidates. Wen Qiufang's model for communicative interview can be classified as follows (1999, p.46):

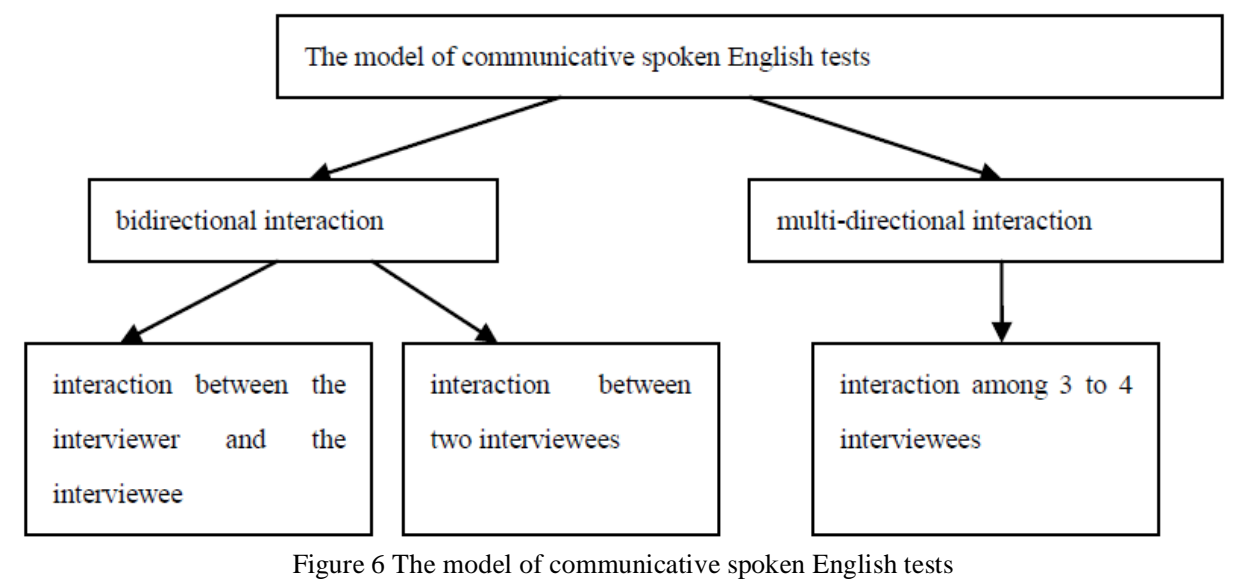

Today, some large-scale spoken English tests such as BEC, IELTS, and TEM-4 spoken English test have adopted such communicative approaches with supervised interactions between the interviewer and the interviewee or interactions between different interviewees (Xu \& Xie, 2006, p.97), but some examinations such as the spoken English test for Shanghai College Entrance Examination is still implemented in the structural approach in a uni-directional approach. The candidates listen to the directions from the earphones, study the pictures on the computer screen before them, and respond to questions. Their responses are recorded in the computer and stored for future evaluation. The test is composed of the following sections (Zhang, 2004):

Part 1: Quick Response (10\%)

Part 2: Question Raising (20\%)

Part 3: Reading (10\%)

Part 4: Topic Talking (30\%)

Part 5: Picture Describing (30\%)

Communicative skills are tested in Quick Response section in which candidates are required to make proper responses quickly to the communicative situation, but they are not allowed to raise any question as follow-up. In classroom teaching, such responses have been taught and habitualized so that candidates just make automatic responses to regular questions such as invitations, making apologies and talking about hobbies. However, whether or not they can react to new questions in the communicative situation remains unknown. Part 2 and 3 are solely about the linguistic skills. There is no interaction in Part 4 and 5 either. This spoken English test is a typical one in China today. In light of this, the interactional competence still deserves enough attention from teachers and researchers.

In many Chinese universities, spoken English tests have also been implemented either in a uni-directional approach or in the format of conversation between the interviewer and the interviewee. The author suggests that in the light of interactional competence, students should be allowed to interact with each other in a team of two or three during the interview, thereby creating a complete loop of conversation. In this way students will better utilize their expertise of conversational strategies and create a virtual environment for communicative functions. The interviewer can also make better holistic judgment about their spoken English performance by studying the whole loop of conversation and all the conversational strategies involved. 


\section{CONCLUSION}

Communicative competence as a concept that derives from the dichotomy of linguistic competence and linguistic performance by Noam Chomsky has been widely accepted and extensively studied during the past three decades, but the teaching of spoken English in China has largely neglected the development of strategic competence. By shifting to interactional competence in a constructivist approach, teachers and researchers can gain better insight into the acquisition of spoken competence. Thus two hints are discovered for today's spoken English teachers: first, conversational strategies should constitute an integral part in teaching spoken English because they are the lubricants for smooth turn-taking and shifts; second, priority in spoken English teaching and testing should be given to complete conversational loops because the loop as an integral unit for conversation can best display the speakers' co-construction of strategic competence and communicative skills. A strategy-reinforced interaction that is taught in the form of complete conversational loops will hopefully strengthen students' competence for handling these interactional activities and achieve better communicative competence.

To achieve this goal, classroom teaching alone does not suffice. As shown in Table 1, communicative strategies are not yet included in the university textbooks for spoken English teaching. Without authoritative resources for the teaching of communicative strategies, it will be hard for teachers to implement them in classroom teaching. As a consequence, it is no wonder that students show poor awareness of communicative strategies in spoken English tests. Therefore it is advisable that such a strategy-reinforced interactional approach should be implemented throughout all components of college English teaching-from textbook compilation, classroom teaching to testing. A textbook compiled under the guidance of this principle will hopefully enhance the effect of spoken English teaching in the classroom, which will be examined and verified subsequently in spoken English tests. Such a reform to spoken English teaching will be an enormous systematic project and will not be made possible without due concern and support from language teachers and researchers. Therefore it is expected that this paper will contribute to better knowledge of communicative competence in the light of strategy-reinforced interactions and hence improve the teaching efficiency throughout all components of spoken English teaching in Chinese universities.

\section{ACKNOWLEDGMENT}

The author wishes to thank Prof. Donglin Qiu for his guidance and support.

\section{REFERENCES}

[1] Bachman,L . F. (1988) Language testing - SLA research interfaces. Annual Review of Applied Linguistics, (9), $193-209$.

[2] Bachman, L. F. (1990). Fundamental considerations in language testing. New York: Oxford University Press.

[3] Bachman, L. \& Palmer, A. (1982). The construct validation of some components of communicative proficiency. TESOL Quarterly, (16), 449-465.

[4] Bachman, L. F., \& Palmer, A. S. (1996). Language testing in practice. Oxford: Oxford University Press.

[5] Canale, M., \& Swain, M. (1980). Theoretical bases of communicative approaches to second language teaching and testing. Applied linguistics, 1(1), 1-47.

[6] Chen, C. (2003). Critical Analysis of the Theory of Communicative Competence. Foreign Languages Research, (2), 93-97.

[7] Gao, Y. (2002). On Development of Pragmatic Competence and Improvement of Oral English Proficiency. Computer-assisted Foreign Language Education. (2), 6-9.

[8] Guo, Z. (2002). From "One-way Presentation" to "Interactive Communication". Foreign Languages and Their Teaching, (6), $22-25$.

[9] Hall, J. K. (1995). (Re) creating our worlds without words: A sociohistorical perspective of face-to-face interaction. Applied Linguistics, 16(2), 206-232.

[10] He, A. \& R. Young. (1998) Language proficiency interviews: A discourse approach. in R. Young and W. He (eds): Talking and Testing: Discourse approaches to the assessment of oral proficiency. Philadelphia: John Benjamins, 1-24.

[11] Higher Education Department of the Ministry of Education. (2007). College English Curriculum Requirements. http://www.chinanews.com/edu/kong/news/2007/09-26/1036802.shtml (Accessed 10/2/2014).

[12] Hymes, D. (1971). On linguistic theory, communicative competence, and the education of disadvantaged children. In M.L. Wax, S.A. Diamond \& F. Gearing (Eds.), Anthropological perspectives on education. New York: Basic Books. 51-66.

[13] Hymes, D.H. (1972). On communicative competence. In J.B. Pride \& J. Holmes (Eds.), Sociolinguistics. London: Penguin. 269-293.

[14] Jacoby, S., \& Ochs, E. (1995). Co-construction: An introduction. Research on language and social interaction, 28(3), 171-183.

[15] Kong, J. (2004). A Study of Communication Strategy Training. Foreign Languages World, (5), 33-39.

[16] Kramsch, C. (1986). From language proficiency to interactional competence. The Modern Language Journal, 70(4), 366-372.

[17] Levinson, S. C. (1983). Pragmatics, Cambridge: Cambridge University Press.

[18] Li, C. (2003). Discourse Management and Strategic Competence in Raising Oral Communicative Competence --An Analysis of BEC Speaking Test. Foreign Language Education, (1), 63-65.

[19] Savignon, S. J. (1983). Communicative Competence: Theory and Classroom Practice. Texts and Contexts in Second Language Learning. Reading, MA: Addison-Wesley Publishing Company.

[20] Sercu, L., \& Bandura, E. (2005). Foreign language teachers and intercultural competence: An international investigation (Vol. 10). London: Multilingual Matters. 
[21] Verhoeven, L., \& Vermeer, A. (2002). Communicative competence and personality dimensions in first and second language learners. Applied Psycholinguistics, 23(03), 361-374.

[22] Wang, L. (2002). An experiment on teaching of communication strategies to Chinese EFL learners. Foreign Language Teaching and Research, 34(6), 426-430.

[23] Wang, L. (2004). 12 Years of Research in English Speaking in China: Retrospect and Current Situations. Foreign Language World, (6), 7-14.

[24] Wang, S. (2001) Accuracy, Appropriateness, Improvement, Deepening: Approach to the Compilation of A New Oral English Course. Foreign Language World, (2), 68-71.

[25] Wen, Q. (1999). Testing \& Teaching Spoken English. Shanghai: Shanghai Foreign Language Education Press.

[26] Xu, H. \& Xie, Z. (2006). A Theoretical Analysis of the National Oral Test for English Majors. Journal of Nanjing Normal University(Social Science Edition), (2), 92-98.

[27] Yang, H. \& Wei, N. (2005). Construction and Research of College Learners Spoken English Corpus (COLSEC). Shanghai: Shanghai Foreign Language Education Press.

[28] Young, R. (1999). Sociolinguistic approaches to SLA. Annual Review of Applied Linguistics, (19), 105-132.

[29] Yu, S., \& Li, H. (2002). Students Book, College English-Listening and Speaking Course 2. Shanghai: Shanghai Foreign Language Education Press.

[30] Zeng, L \& Li, C. (2005). Developing Spoken English Communicative Skills with Simulated Scenario Dialogues: An Experiment Report on Training of Communicative Strategies. Foreign Language World, 108(4), 42-47.

[31] Zhang, H. (2006). Intercultural Approach to Foreign Language Teaching. Shanghai: Shanghai Foreign Language Education Press.

Dongyun Sun is currently a lecturer in the College English Center of Fudan University. Her research interests include applied linguistics, language planning and policy, and educational linguistics. She worked as an adjunct professor of Chinese language in the University of North Carolina, Wilmington from 2009 to 2010. 